\title{
Use of a radiopaque localizer grid to reduce radiation exposure
}

Kee D Kim ${ }^{1,3^{*}}$, Wentao Li $^{2}$ and Caren L Galloway ${ }^{1}$

\begin{abstract}
Background: Minimally invasive spine surgery requires placement of the skin incision at an ideal location in the patient's back by the surgeon. However, numerous fluoroscopic $x$-ray images are sometimes required to find the site of entry, thereby exposing patients and Operating Room personnel to additional radiation. To minimize this exposure, a radiopaque localizer grid was devised to increase planning efficiency and reduce radiation exposure.

Results: The radiopaque localizer grid was utilized to plan the point of entry for minimally invasive spine surgery. Use of the grid allowed the surgeon to accurately pinpoint the ideal entry point for the procedure with just one or two fluoroscopic X-ray images.

Conclusions: The reusable localizer grid is a simple and practical device that may be utilized to more efficiently plan an entry site on the skin, thus reducing radiation exposure. This device or a modified version may be utilized for any procedure involving the spine.
\end{abstract}

Keywords: Radiation, Exposure, Minimally Invasive, Spine Surgery, Localization, Innovation, Grid

\section{Introduction}

Decreased soft tissue trauma and quicker patient recovery time have garnered wider support and popularity for minimally invasive spine surgery [1]. Demarcating the ideal entry point on the skin is a critical step for the success of the minimally invasive procedure. A suboptimal entry point leads to inadequate exposure of the surgical site. This is associated with increased operative time, complications or possible inability to perform the procedure [1-6].

Traditional methods using radiopaque markers such as K-wires, or surgical instruments such as towel clamps require numerous radiographic images in a trial-anderror fashion. Radiopaque markers are placed on a patient's back at the surgeon's discretion and fluoroscopic antero-posterior (AP) X-ray images are obtained. These markers, depending on their location in relation to the desired target on the spine, would then be rearranged. Additional images are obtained until the surgeon is able to mark out the ideal entry site on the patient's back for that particular procedure. K- wires

\footnotetext{
* Correspondence: kee.kim@ucdmc.ucdavis.edu

'Department of Neurological Surgery, University of California, Davis, 4860 Y

Street Suite 3740, Sacramento, CA 95816, USA

Full list of author information is available at the end of the article
}

could move during these steps, necessitating even more images. However, additional use of fluoroscopic X-ray images during localization results in increased radiation exposure to both patients and surgical staff [7-10].

While radiation exposure and risk to spine surgeons and medical personnel have not been adequately documented, an increased incidence of thyroid cancer among orthopedic surgeons has been noted [10]. Spine surgeons are especially at risk from increased radiation exposure [7]. One estimate puts a surgeon's risk of cancer to be five times that of other hospital employees. In addition, surgeons typically receive two to three times the radiation dose of patients [8].

With the advent of minimally invasive spine surgery and increased use of fluoroscopy, there is greater sensitivity to radiation exposure. In 2003, the senior author (KDK) devised a simple radiopaque grid to decrease the number of fluoroscopic images necessary to start the procedure, thus decreasing the radiation exposure.

\section{Methods}

The localizer grid in its current iteration is a $165 \times 178$ $\times 2 \mathrm{~mm}$ radiopaque grid fashioned out of titanium alloy, split evenly in to smaller rectangles by length and width-wise bars, spaced $9 \mathrm{~mm}$ and $15 \mathrm{~mm}$ apart, 


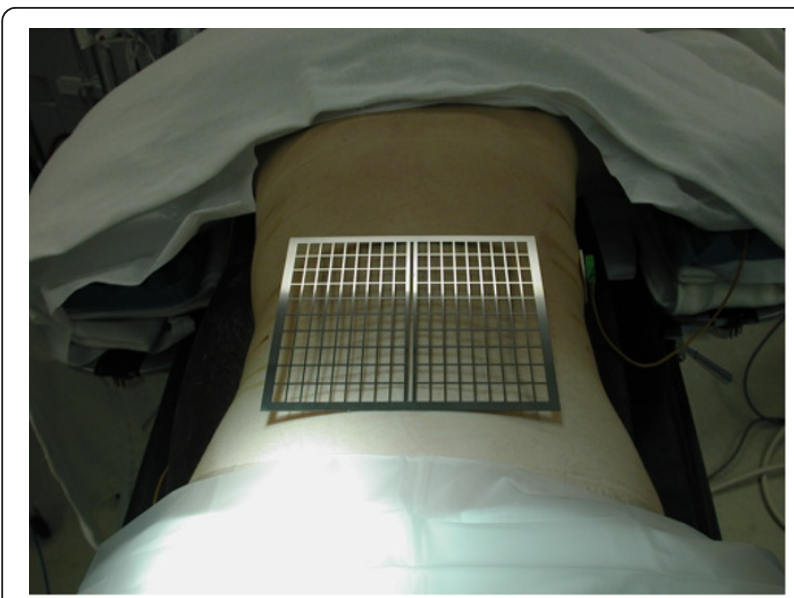

Figure 1 To determine, ideal site of entry, a radiopaque grid is placed intraoperatively on patient's low back centered over the spine.

respectively (Figure 1). Generous space within the localizer allows a marker or pen tip to be placed directly on the skin without displacing the grid. Finally, to facilitate alignment with the center of the spine, the grid is bisected down the middle by a hollow $9 \mathrm{~mm}$ center divide. This hollow center allows for better visualization of the spinous process.

The radiopaque grid is physically placed on the patient's back with the central gap in the midline over the approximate spinal levels of interest. The AP fluoroscopic X-ray image is then obtained. The single image on the monitor provides the image of the spine in relation to the grid (Figure 2). Based on this spatial relationship, a marker may be utilized to demarcate an ideal site on the patient's back to perform a minimally invasive procedure.

\section{Results}

With the use of the radiopaque localizer grid, one or two images are sufficient to determine the ideal entry site instead of six to twelve images typically obtained prior to its use. The following are two illustrative cases where the radiopaque grid was utilized.

The first case involves a patient who underwent L4 to S1 instrumented fusion. With the use of the grid, we were able to determine the site for an ideal skin incision with a single AP image (Figure 3). We performed twolevel instrumented fusion using paramedian skin incisions measuring about $3.5 \mathrm{~cm}$ each (Figure 4). Another example involves radiofrequency facet denervation, most often performed by interventional pain specialists. With the use of the grid, only one AP fluoroscopic image was needed to demarcate ideal needle entry points (Figures 5 and 6). This patient required twelve lesioning needles

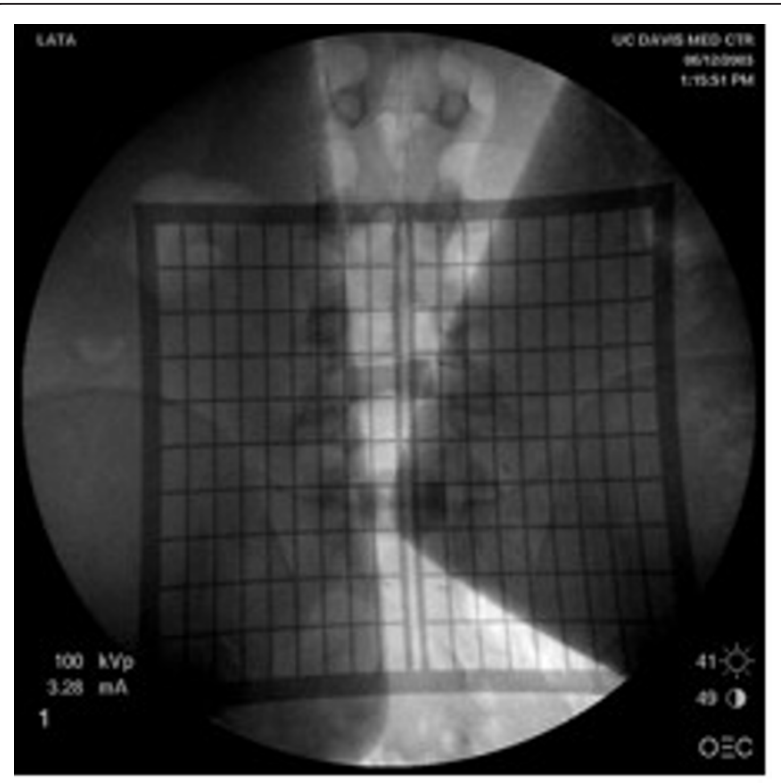

Figure 2 AP fluoroscopic image obtained shows the relationship of the grid to patient's lumbar spine. Based on this image, the incision for the minimally invasive procedure may be accurately marked prior to surgery.

to be placed on his back. Without the grid, multiple fluoroscopic images would have been necessary.

\section{Conclusions}

Minimally invasive spine procedures depend on the use of fluoroscopic X-rays for the accurate localization of the incision site. Even with the use of lead aprons and thyroid shields, body parts are exposed to radiation. Our

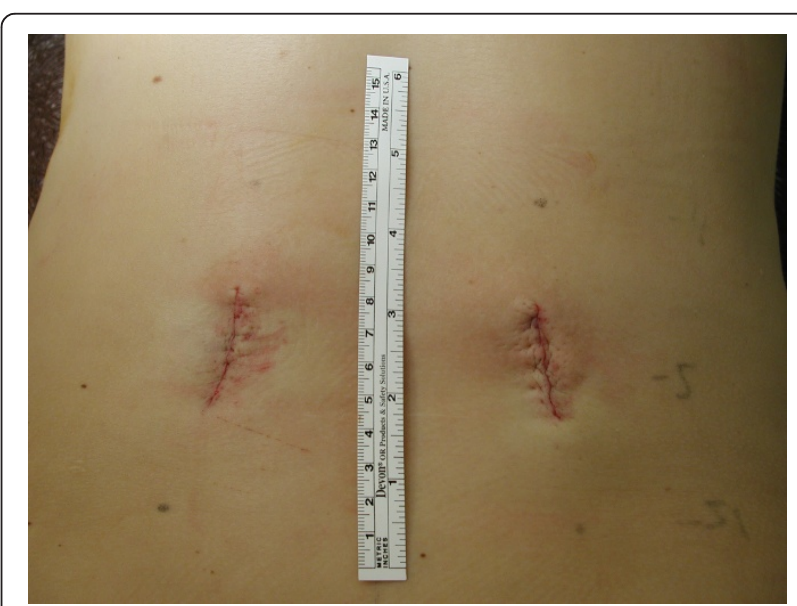

Figure 3 Intraoperative photograph shows small paramedian skin incisions on a patient who underwent L4 to S1 instrumented fusion. The grid was utilized to mark the ideal skin incision for this minimally invasive spine surgery. 


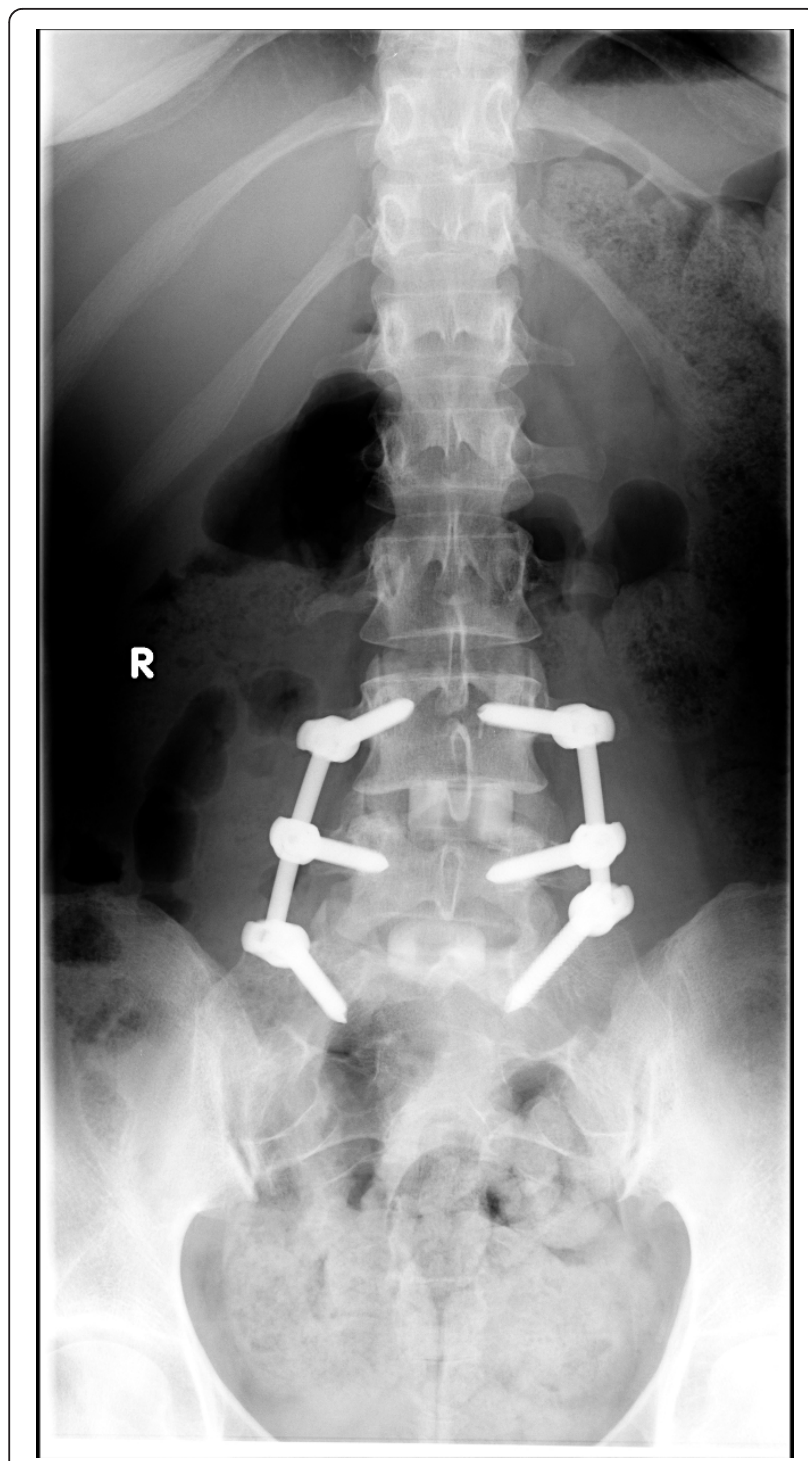

Figure 4 AP X-ray shows L4 to S1 instrumented fusion using minimally invasive approach. In order to perform this type of surgery, the location of skin incision must be very precise.

localizer grid was devised to decrease total radiation exposure to the patient and Operating Room personnel. Its use also allowed a slight decrease in total operative time.

Our experience has demonstrated the localizer grid to be an effective aid in fluoroscopic planning for minimally invasive spine surgery, or any interventional pain procedure targeting the spine. This grid may be easily modified from its current dimension or material to allow greater use. For example, a moldable and sterilizable version may give greater flexibility in its use.

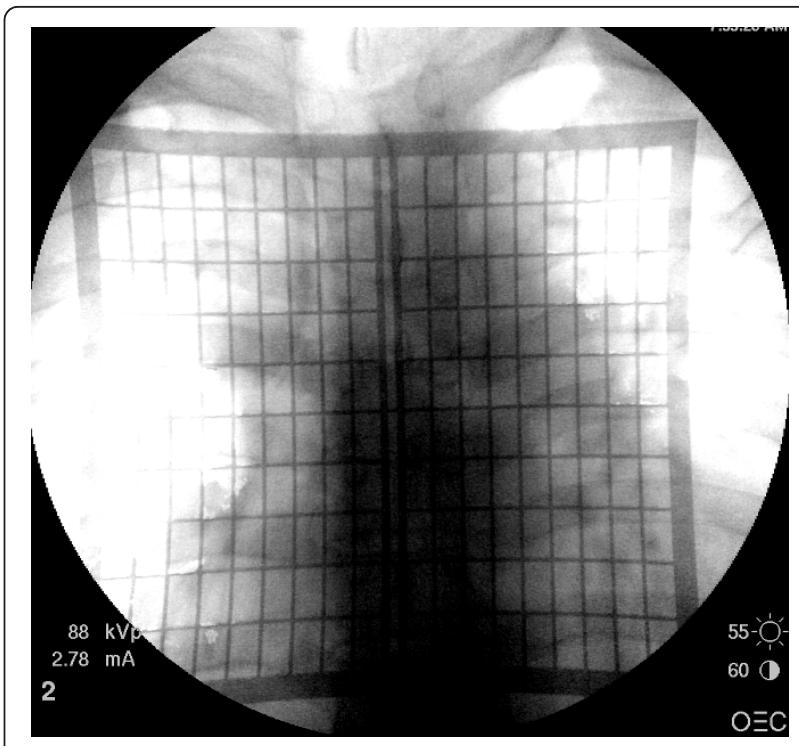

Figure 5 AP fluoroscopic image shows the relationship of the grid with the thoracic spine.

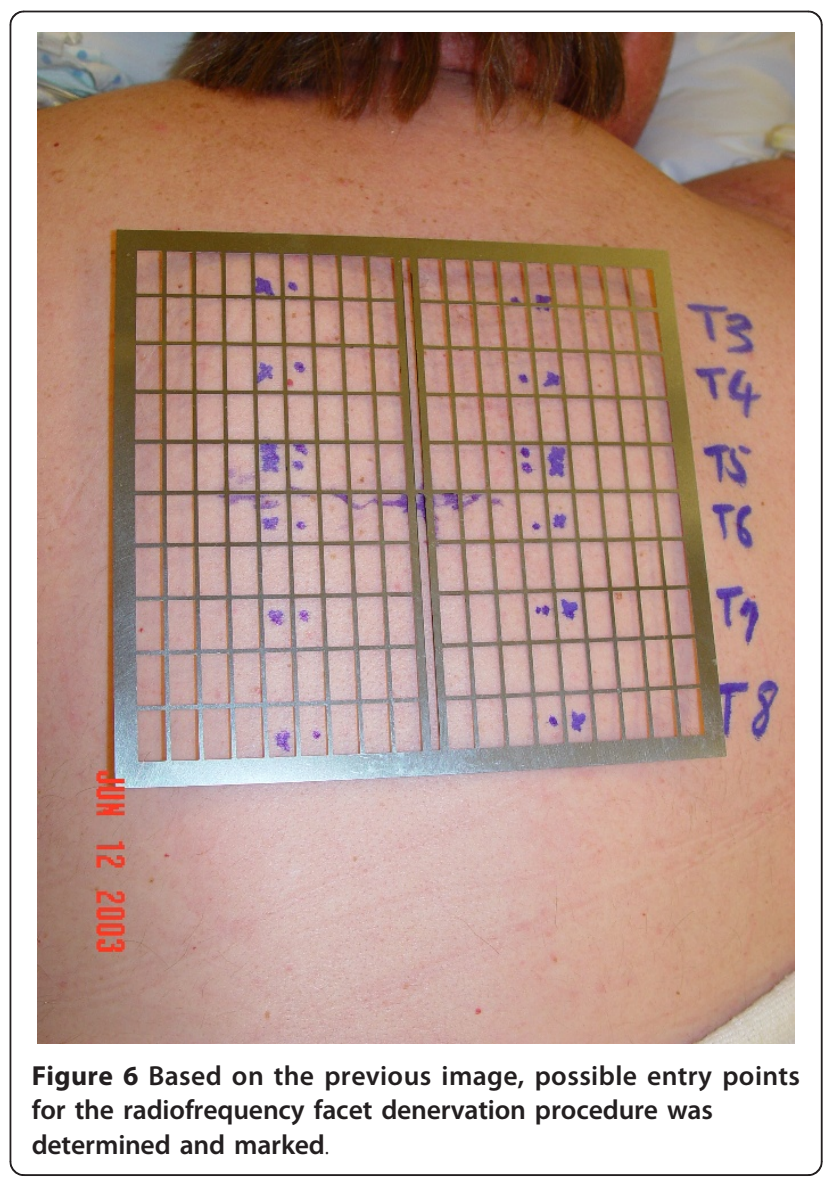




\section{Acknowledgements and funding}

We would like to acknowledge Philip Lee for help with the preparation of this manuscript. No funding was received. All authors have read and approved the final manuscript.

\section{Author details}

'Department of Neurological Surgery, University of California, Davis, 4860 Y Street Suite 3740, Sacramento, CA 95816, USA. ${ }^{2}$ Department of Molecular and Cell Biology, University of California, Berkeley, 142 LSA \#3200, Berkeley, CA 94720, USA. ${ }^{3}$ Department Neurological Surgery, University of California, Davis, 4860 Y Street Suite 3740, Sacramento, CA 95816, USA.

\section{Authors' contributions}

KDK devised the instrument discussed, took images and edited the manuscript.

WL performed literature review and wrote substantial portion of the manuscript.

CG revised manuscript

\section{Authors' information}

KDK is an Associate Professor of Neurological Surgery and Chief of Spinal Neurosurgery at University of California, Davis USA.

CG is clinical research coordinator at UC Davis Spine Center

\section{Competing interests}

The authors declare that they have no competing interests.

Received: 27 May 2011 Accepted: 9 August 2011

Published: 9 August 2011

\section{References}

1. Cleary K, Clifford M, Stoianovici D, Freedman M, Mun SK, Watson V: Technology improvements for image-guided and minimally invasive spine procedures. IEEE Trans Inf Technol Biomed 2002, 6(4):249-61.

2. Barrett C, English P, Evans J, Mitra D, Todd NV: Intra-operative MRI-assisted spinal localization. Acta Neurochir (Wien) 2010, 152(4):669-73.

3. Cornips E, Beuls E, Geskes G, Janssens M, van Aalst J, Hofman P. Preoperative localization of herniated thoracic discs using myelo-CT guided transpleural puncture: technical note. Childs Nerv Syst 2007, 23(1):21-6.

4. Binning MJ, Schmidt MH: Percutaneous placement of radiopaque markers at the pedicle of interest for preoperative localization of thoracic spine level. Spine (Phila Pa 1976) 2010, 35(19):1821-5.

5. Nowitzke A, Wood M, Cooney K: Improving accuracy and reducing errors in spinal surgery-a new technique for thoracolumbar-level localization using computer-assisted image guidance. Spine J 2008, 8(4):597-604

6. Müller A, Gall C, März U, Reulen HJ: A keyhole approach for endoscopically assisted pedicle screw fixation in lumbar spine instability. Neurosurgery 2000, 47(1):85-95,

7. Mroz TE, Abdullah KG, Steinmetz MP, Steinmetz MP, Klineberg EO, Lieberman $I \mathrm{H}$ : Radiation Exposure to the Surgeon During Percutaneous Pedicle Screw Placement. J Spinal Disord Tech 2010, Available from: Swets Information Services, Accessed March 24, 2011

8. Giordano BD, Baumhauer JF, Morgan TL, Rechtine GR: Cervical spine imaging using standard C-arm fluoroscopy: patient and surgeon exposure to ionizing radiation. Spine (Phila Pa 1976) 2008, 33(18):1970-6.

9. Kim TW, Jung JH, Jeon HJ, Yoon KB, Yoon DM: Radiation exposure to physicians during interventional pain procedures. Korean J Pain 2010, 23(1):24-7.

10. Delbridge L, Learoyd D: Radiation exposure, thyroid cancer and surgeons. ust N Z J Surg 1998, 68(9):627.

doi:10.1186/1750-1164-5-6

Cite this article as: Kim et al:: Use of a radiopaque localizer grid to reduce radiation exposure. Annals of Surgical Innovation and Research 2011 5:6.

\section{Submit your next manuscript to BioMed Central and take full advantage of:}

- Convenient online submission

- Thorough peer review

- No space constraints or color figure charges

- Immediate publication on acceptance

- Inclusion in PubMed, CAS, Scopus and Google Scholar

- Research which is freely available for redistribution

Submit your manuscript at www.biomedcentral.com/submit
Biomed Central 